\title{
The rate of unnecessary interventions for the management of knee osteoarthritis: a population- based cohort study
}

\author{
Jacquelyn D. Marsh, PhD \\ Ryan Degen, MD \\ Trevor B. Birmingham, PhD \\ J. Robert Giffin, MD, MBA \\ Alan Getgood, MD \\ Robert Litchfield, MD \\ Kevin Willits, MD \\ J. Andrew McClure, MSc \\ Blayne Welk, MD, MSc
}

Accepted March 3, 2021

\author{
Correspondence to: \\ J. Marsh \\ Faculty of Health Sciences \\ University of Western Ontario \\ 1201 Western Road, Room 1400 \\ London ON N6G1H1 \\ jmarsh2@uwo.ca
}

Cite as: Can J Surg 2022 February 17; 65(1). doi:10.1503/cjs.002221

\begin{abstract}
Background: Several commonly used procedures for knee osteoarthritis (OA) are not supported by evidence-based guidelines. The objective of this study was to identify the proportion of patients who underwent knee arthroscopy or magnetic resonance imaging (MRI) and the timing of these procedures before total knee arthroplasty (TKA).
\end{abstract}

Methods: We conducted a retrospective cohort study using administrative data sets from Ontario, Canada. We identified the proportion of patients who underwent knee arthroscopy in the previous 10 years or an MRI in the 3 years before their primary TKA. We also evaluated the rate of arthroscopies by diagnosis. We report the timing of each outcome in relation to the TKA, rates by geographical area, and differences in rates over time.

Results: We included 142275 patients, of whom 36379 (25.57\%) underwent knee arthroscopy (median time 2.8 [interquartile range (IQR) 1.1-6.0] years); $22 \%$ of those were within 1 year of TKA and $52 \%$ were within 3 years. The rates of arthroscopies for a diagnosis of osteoarthritis (OA) steadily decreased, while those for meniscal-related diagnoses increased over the study period $(p<0.0001)$. There was significant variation by region. Of the cohort, $23.2 \%(n=32989)$ had an MRI before their TKA, with rates significantly increasing over time $(p<0.0001)$.

Conclusion: A substantial proportion of patients with knee OA received diagnostic and therapeutic interventions before TKA that are contrary to clinical practice guidelines.

Contexte : Plusieurs interventions diagnostiques ou thérapeutiques d'usage courant pour l'arthrose du genou ne s'appuient sur aucune ligne directrice fondée sur des données probantes. L'objectif de cette étude était d'établir la proportion de patients qui ont subi une arthroscopie ou une épreuve d'imagerie par résonnance magnétique (IRM), et l'intervalle entre ces interventions et l'arthroplastie pour prothèse totale du genou (PTG).

Méthodes : Nous avons procédé à une étude de cohorte rétrospective à partir de données administratives de population en Ontario, au Canada. Nous avons établi la proportion de patients soumis à une arthroscopie du genou dans les 10 années ou une IRM dans les 3 années précédant une PTG primaire. Nous avons aussi calculé le taux d'arthroscopies par diagnostic. Nous faisons état du moment de chacune par rapport à la PTG, des taux par région, et les différences de taux avec le temps.

Résultats : Nous avons inclus 142275 patients, dont 36379 (25,57\%) ont subi une arthroscopie du genou (intervalle médian 2,8 ans [intervalle interquartile (IIQ) 1,1-6,0]); $22 \%$ d'entre eux ont reçu leur PTG dans l'année suivante et $52 \%$ dans les 3 années suivantes. Les taux d'arthroscopies pour un diagnostic d'arthrose ont régulièrement diminué, tandis que les diagnostics liés à des problèmes de ménisque ont augmenté pendant la période de l'étude $(p<0,0001)$. On a noté une variation significative d'une région à l'autre. Dans cette cohorte, $23,2 \%$ des patients $(n=32989)$ avaient subi une IRM avant leur PTG, avec des taux significativement croissants avec le temps $(p<0,0001)$.

Conclusion : Dans une proportion substantielle, les patients souffrant d'arthrose du genou ont subi des interventions diagnostiques et thérapeutiques pré-PTG qui sont contraires aux lignes directrices de pratique clinique. 


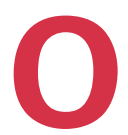
steoarthritis (OA) of the knee is one of the most common chronic health conditions and is a leading contributor to health care service use. ${ }^{1-3}$ The disease typically involves slow degeneration of knee joint tissues and progressive symptoms, ultimately resulting in deterioration of the joint. ${ }^{4}$ Surgical replacement of the joint through total knee arthroplasty (TKA) improves symptoms for most patients with end-stage knee OA. Before end-stage disease, patients undergo numerous assessments and interventions aimed at improving symptoms and delaying disease progression.

Several commonly used treatments for knee OA are not supported by evidence-based guidelines. Notably, knee arthroscopy is often performed to treat degenerative meniscal pathology, a common feature of OA, yet substantial high-quality evidence showing a lack of clinical improvement and cost-effectiveness ${ }^{5-12}$ has led to recommendations against the use of arthroscopy in patients with degenerative knee disease. ${ }^{13-18}$

Physical examination, history and weight-bearing radiographs are recommended to diagnose knee OA and guide treatment choices. ${ }^{19,20}$ Importantly, MRI is not recommended for the diagnosis or management of OA, yet patients are often referred for an MRI that is considered unnecessary by orthopedic specialists. ${ }^{21}$ Previous retrospective studies have shown that few patients with knee pain have a weight-bearing radiograph before receiving an MRI. ${ }^{21}$ Moreover, MRIs often detect incidental findings, such as degenerative meniscal tears that are common among middle-aged individuals with or without knee symptoms, likely do not contribute to pain and should not change management. ${ }^{22-25}$

Clinical practice guidelines provide recommendations on appropriate interventions for the diagnosis and treatment of knee $\mathrm{OA}^{13-18}$ based on the best available research evidence and reviewed by panels of international experts. However, the extent to which such guidelines are followed is unclear. Many of the nonrecommended treatments for knee OA appear to remain in common use and may occur within close proximity to total joint replacement, perhaps contributing to unnecessary health care expenditures on top of those required for the TKA.

The objective of this study was to identify the proportion of patients with knee OA who underwent knee arthroscopy or MRI and the timing of these procedures before TKA.

\section{Methods}

We conducted a retrospective cohort study using administrative data sets accessed through ICES (formerly the Institute for Clinical Evaluative Sciences). We included all Ontario residents who underwent an elective, primary TKA for osteoarthritis between April 1, 2007, and March 31, 2017. The Ontario Health Insurance Plan (OHIP) provides universal health coverage for medical services to all Ontario residents. We used OHIP physician billing records to identify the initial cohort. We excluded patients younger than 40 years, as well as those who had undergone a TKA within the previous 15 years. We also excluded patients if we were unable to identify a hospital admission record for the procedure or if the hospital record for TKA did not include a diagnosis of OA.

We collected baseline variables including age, sex, location of residence, income quintile and Charlson Comorbidity Index, using a 3-year look-back period before the primary TKA. Location of residence was assigned according to the 14 health administrative boundaries, Local Health Integration Networks (LHINs), that are used to administer health care throughout the province. We also recorded medical comorbidities including coronary heart failure, ${ }^{26}$ chronic obstructive pulmonary disease, ${ }^{27}$ hypertension, ${ }^{28}$ diabetes, ${ }^{29}$ rheumatoid arthritis, ${ }^{30}$ depression and obesity. Depression was defined as any psychiatric visit or hospital admission for depression or 2 visits to a general practitioner for depression within a 2 -year period. Obesity was defined as any physician visit for obesity or hospital admission with a corresponding diagnosis code for obesity in the 3 years before the TKA.

\section{Data sources}

The administrative data sources used for this study include the Canadian Institute for Health Information Discharge Abstract Database/Same Day Surgery (CIHIDAD/SDS), which includes all hospital-based admissions for diagnostic and surgical procedures; OHIP, which contains all physician fee-for-service billing requests for patient encounters and procedures; and the Registered Persons Database (RPDB), for demographic information including age, gender, income and geographic location. Data sets were linked using unique, encoded identifiers. A full list of the codes used is provided in a supplemental table (Appendix 1, available at www.canjsurg.ca/lookup/ doi/10.1503/cjs.002221/tab-related-content).

Patient-level data were linked across databases with unique encoded identifiers. The use of these data was authorized under Ontario's Personal Health Information Protection Act, which does not require review by a research ethics board, and thus patient consent was not required. Our reporting follows the guidelines of the Reporting of Studies Conducted Using Observational Routinely Collected Data (RECORD) statement (Appendix 2, available at www.canjsurg.ca/lookup/ doi/10.1503/cjs.002221/tab-related-content). ${ }^{31}$ 


\section{Procedures}

\section{Arthroscopy}

We first identified the rates and timing of knee arthroscopy within 10 years before the primary TKA, identified by either a hospital or physician billing record for the procedure. For patients with a hospital-based procedure, we were also able to capture diagnoses associated with the admission. The patient diagnosis recorded as most responsible for the admission was categorized into 4 mutually exclusive categories: 1) osteoarthritis/gonarthrosis; 2) meniscal-related, 3) pain in joint, and 4) other (not belonging to any of the first 3 diagnoses). If patients had more than 1 diagnosis recorded with the procedure, we placed them in the first category of our defined hierarchy.

\section{MRI}

We identified patients who had received an MRI in the 3 years before their TKA. We identified MRI using OHIP physician billing codes. Currently, there is not a specific OHIP code for an MRI of the knee joint; therefore, we identified any incidence of the OHIP fee code for an MRI of an extremity or joint.

\section{Statistical analysis}

We used descriptive statistics to describe the number of arthroscopies and MRIs per year over the study period as well as the timing of each outcome in relation to the TKA. For knee arthroscopy, we also evaluated the rate of the procedure by corresponding diagnosis code for each year over the study period. We also reported the proportion of patients in the cohort who underwent each outcome by geographical area (LHIN). We used the Cochran-Armitage $\chi^{2}$ test to assess differences in rates over time.

\section{Results}

During the study accrual period, 166996 patients met the coding criteria for study inclusion, of which 24721 $(14.8 \%)$ patients were excluded. The resulting study cohort contained 142275 patients (Figure 1). The average age of the cohort was $67.64 \pm 9.31$ years, and $62.2 \%$ of patients were female (Table 1). In general, the comorbidities did not vary between groups that had different interventions before the TKA.

A total of 36379 (25.57\%) patients in the cohort had undergone an arthroscopic knee procedure over the study period, with 8147 of the total TKA cohort (5.7\%) undergoing the procedure in the 1 year prior, and $18777(13.2 \%)$ in the 3 years before their primary TKA. The percentage of patients who underwent a previous arthroscopy gradually decreased over the study period, from $28.8 \%$ in 2007 to $21.9 \%$ in 2016 $(p<0.0001$; Figure 2). The proportion of knee arthroscopies performed for a corresponding diagnosis code of OA steadily decreased each year, while the proportion of knee arthroscopies performed for a corresponding diagnosis code of meniscal-related diagnoses increased over the same period $(p<0.0001)$ (Figure 3). Median time from arthroscopy to TKA was 2.8 (IQR 1.1-6.0) years, with $22.4 \%(8147 / 36379)$ of the arthroscopies occurring within 1 year and $51.6 \%(n=18777)$ occurring within 3 years. Further, there was significant variation in the rates of knee arthroscopies by region $(p<0.001)$ (Figure 4).

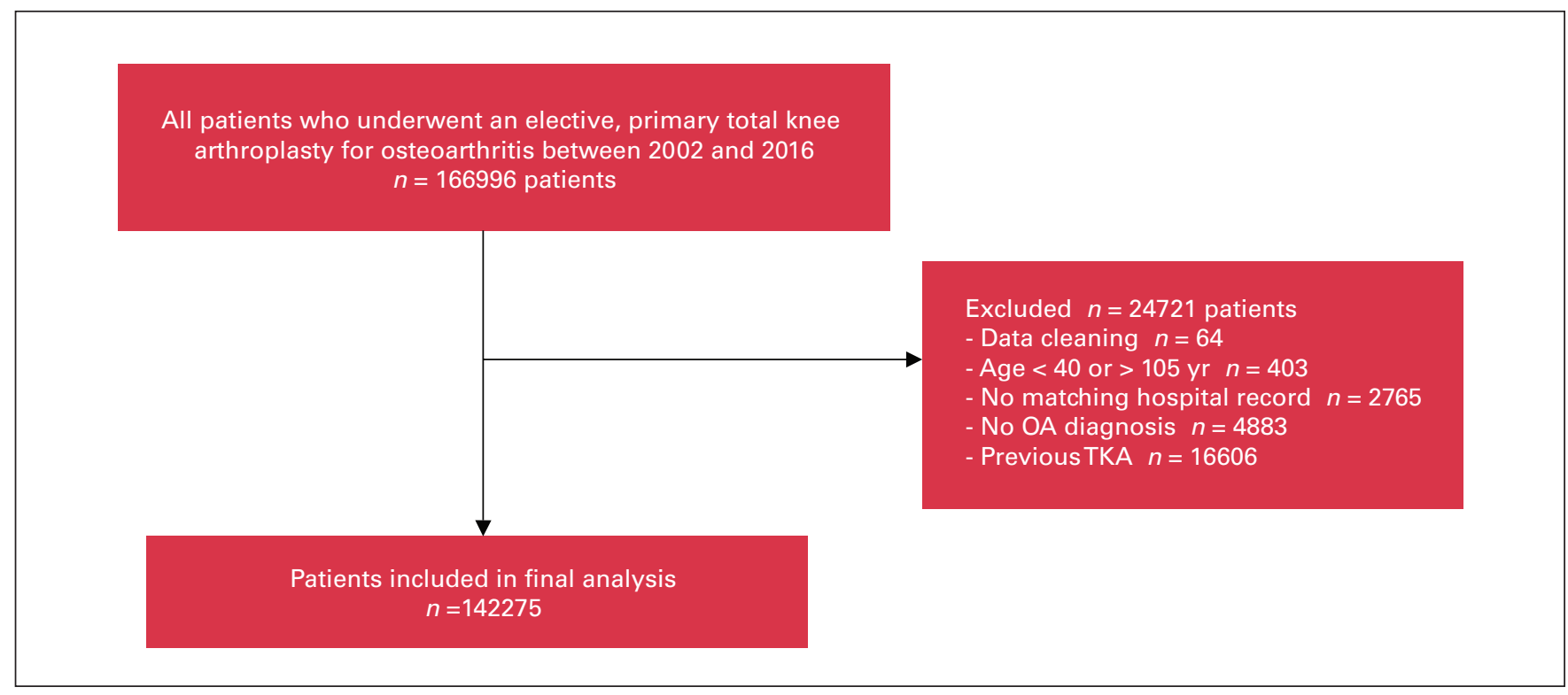

Fig. 1. Cohort development flow chart. $O A=$ osteoarthritis; TKA = total knee arthroplasty. 


\begin{tabular}{|c|c|c|c|}
\hline Characteristic & $\begin{array}{c}\text { Total cohort } \\
n=142275\end{array}$ & $\begin{array}{c}\text { Patients } \\
\text { receiving } \\
\text { arthroscopy } \\
n=36379\end{array}$ & $\begin{array}{c}\text { Patients } \\
\text { receiving MRI } \\
n=32989\end{array}$ \\
\hline Age $($ mean $\pm S D)$ & $67.64 \pm 9.31$ & $63.61 \pm 8.86$ & $64.86 \pm 8.96$ \\
\hline Sex (\% female) & $62.2 \%$ & $58.4 \%$ & $63.8 \%$ \\
\hline \multicolumn{4}{|l|}{ Income quintilet } \\
\hline $\begin{array}{l}\text { Quintile } 1 \\
\text { (lowest) }\end{array}$ & $17.3 \%$ & $16.1 \%$ & $16.1 \%$ \\
\hline Quintile 2 & $20.5 \%$ & $19.8 \%$ & $19.7 \%$ \\
\hline Quintile 3 & $20.6 \%$ & $20.8 \%$ & $20.3 \%$ \\
\hline Quintile 4 & $20.5 \%$ & $21.1 \%$ & $21.0 \%$ \\
\hline $\begin{array}{l}\text { Quintile } 5 \\
\text { (highest) }\end{array}$ & $20.9 \%$ & $22.1 \%$ & $22.6 \%$ \\
\hline \multicolumn{4}{|l|}{ Comorbidities } \\
\hline $\mathrm{CHF}$ & $4.8 \%$ & $3.4 \%$ & $3.4 \%$ \\
\hline COPD & $18.2 \%$ & $19.2 \%$ & $18.8 \%$ \\
\hline Hypertension & $71.2 \%$ & $65.2 \%$ & $66.3 \%$ \\
\hline Diabetes & $26.3 \%$ & $23.4 \%$ & $23.8 \%$ \\
\hline $\begin{array}{l}\text { Rheumatoid } \\
\text { arthritis }\end{array}$ & $4.4 \%$ & $4.4 \%$ & $5.0 \%$ \\
\hline Depression & $3.8 \%$ & $4.5 \%$ & $4.5 \%$ \\
\hline Obesity & $16.2 \%$ & $18.6 \%$ & $17.7 \%$ \\
\hline $\begin{array}{l}\text { Charlson } \\
\text { Comorbidity Index }\end{array}$ & $0.26 \pm 0.77$ & $0.25 \pm 0.73$ & $0.24 \pm 0.74$ \\
\hline \multicolumn{4}{|l|}{ Region $\ddagger$} \\
\hline 1 & $6.2 \%$ & $8.1 \%$ & $5.9 \%$ \\
\hline 2 & $9.4 \%$ & $7.8 \%$ & $7.6 \%$ \\
\hline 3 & $5.2 \%$ & $4.6 \%$ & $5.1 \%$ \\
\hline 4 & $13.4 \%$ & $14.3 \%$ & $13.5 \%$ \\
\hline 5 & $5.5 \%$ & $4.9 \%$ & $5.7 \%$ \\
\hline 6 & $6.3 \%$ & $6.5 \%$ & $7.1 \%$ \\
\hline 7 & $5.6 \%$ & $4.5 \%$ & $6.5 \%$ \\
\hline 8 & $9.9 \%$ & $8.7 \%$ & $11.5 \%$ \\
\hline 9 & $11.4 \%$ & $13.0 \%$ & $12.4 \%$ \\
\hline 10 & $5.4 \%$ & $4.0 \%$ & $3.3 \%$ \\
\hline 11 & $8.8 \%$ & $6.3 \%$ & $7.9 \%$ \\
\hline 12 & $3.9 \%$ & $5.0 \%$ & $3.9 \%$ \\
\hline 13 & $6.5 \%$ & $8.8 \%$ & $6.8 \%$ \\
\hline 14 & $2.3 \%$ & $3.4 \%$ & $2.8 \%$ \\
\hline $\begin{array}{l}\text { CHF = congestive hear } \\
\text { local health integration } \\
\text { deviation. } \\
\text { *Proportions represen } \\
\text { †Missing income quint } \\
\text { †The geographic LHIN }\end{array}$ & $\begin{array}{l}\text { ilure, } \mathrm{COPD}=\mathrm{chr} \\
\text { work, MRI = mag } \\
\text { e column percenta } \\
\text { data for } 315(0.2 \% \\
\text { resented by each }\end{array}$ & $\begin{array}{l}\text { obstructive pulmo } \\
\text { resonance imagir } \\
\text { ents. } \\
\text { was not reported }\end{array}$ & $\begin{array}{l}\text { disease, } \mathrm{LHIN}= \\
\mathrm{D}=\text { standard } \\
\text { brivacy reasons. }\end{array}$ \\
\hline
\end{tabular}

Overall, $23.2 \%$ ( $n=32989)$ of the patients had an MRI in the 3 years before their TKA. The percentage of patients who underwent an MRI before TKA significantly increased each year, from $13.5 \%$ in 2007 to $26.5 \%$ in $2016(p<0.0001)$ (Figure 2). There was a temporal link between MRI and TKA, with $50 \%$ of MRIs occurring in the year preceding the TKA.

\section{Discussion}

The prevalence of knee $\mathrm{OA}$ is rapidly growing, resulting in increased demands for care and substantial patient and economic burden. Therefore, it is crucial to provide value-based interventions. This study identifies that before TKA, a substantial proportion of patients with knee OA received diagnostic and therapeutic interventions that are not supported by strong evidence and clinical practice guidelines.

Hawker and colleagues ${ }^{32}$ conducted a similar study assessing knee arthroscopy usage in relation to TKA among patients in Ontario. They reported that $5.7 \%$ of patients had an arthroscopy to treat OA in 2002. A similar study evaluated the prevalence of primary TKA after arthroscopic knee débridement among patients aged 50 years or older between 1992 and 1996. They reported that $9.2 \%$ received TKA within a year and $18.4 \%$ within 3 years of their arthroscopy. ${ }^{33}$

Consistent with our results, a previous analysis of historical utilization trends of knee arthroscopy in Ontario between 2003 and 2012 identified an increase in the proportion of arthroscopy procedures for degeneration or derangement of meniscus and a dramatic decrease in the proportion for osteoarthritis. ${ }^{34}$ Although these shifts in practice may reflect an appropriate decline in provision of arthroscopy for OA, it may also suggest a change in diagnostic coding, as degeneration of the meniscus is a feature of OA. In other words, the same types of patients continue to undergo knee arthroscopy, and rates are actually increasing.

Degen and colleagues ${ }^{35}$ reported a significant increase in the use of knee arthroscopy in the United States between 2006 and 2016. Notably, there was also a significant increase in age among patients undergoing meniscectomy, suggesting the procedure continues to be used to treat degenerative meniscal tears that are associated with OA. Dhawan and colleagues ${ }^{36}$ found that $16 \%$ of TKA patients had undergone arthroscopic débridement within 1 year of TKA. A similar evaluation in England ${ }^{37}$ reports that $9.9 \%$ of patients aged 60 years or older who underwent arthroscopic partial meniscectomy received a subsequent TKA within 1 year, and $16.6 \%$ within 2 years.

Our study also identified an increasing proportion of MRIs conducted on patients with a diagnosis of OA before TKA. Although we cannot confirm whether the MRI was performed on the index knee, $50 \%$ of the MRIs occurred in the year preceding the TKA, suggesting it was likely related to the evaluation of the patient for OA or TKA. Magnetic resonance imaging is not routinely required before TKA; thus, performing these unnecessary MRIs incurs further waiting times, can cause unneeded anxiety while waiting for specialist consultation and can delay imaging for patients presenting with pathology more appropriate for MRI examination. Additionally, the information gleaned from these inappropriate imaging studies does not alter management and incurs significant expenses to publicly funded systems or third-party insurers. 


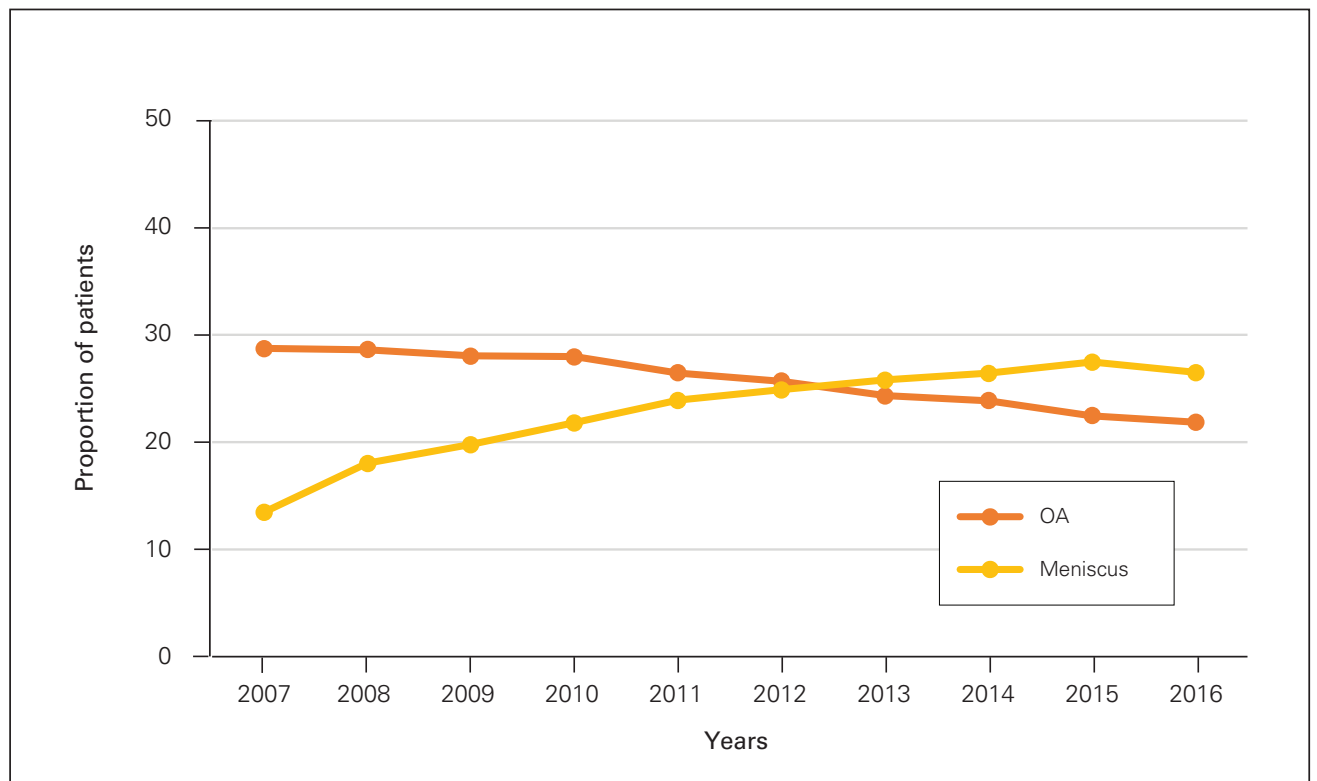

Fig. 2. Proportion of patients who underwent each outcome by fiscal year. MRI = magnetic resonance imaging; $\mathrm{OA}=$ osteoarthritis.

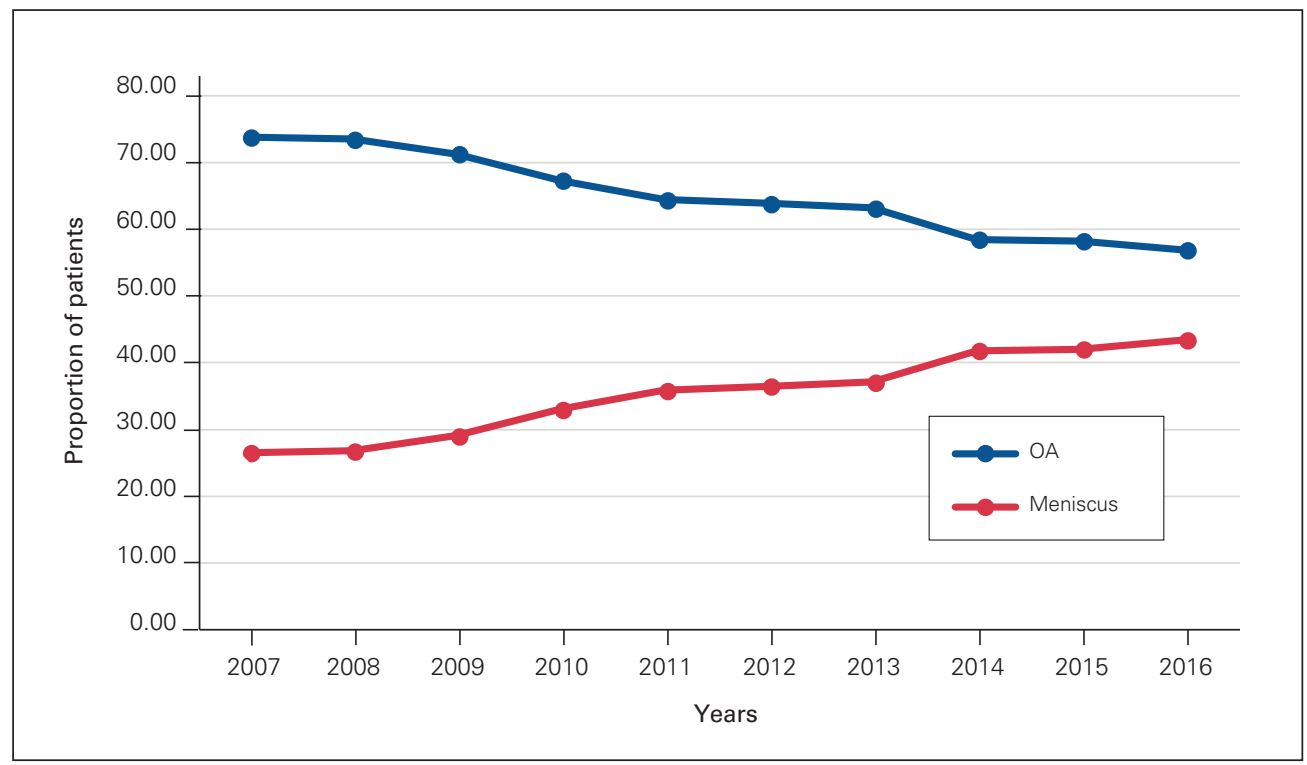

Fig. 3. Rate of arthroscopy by diagnosis and fiscal year. $\mathrm{OA}=$ osteoarthritis.

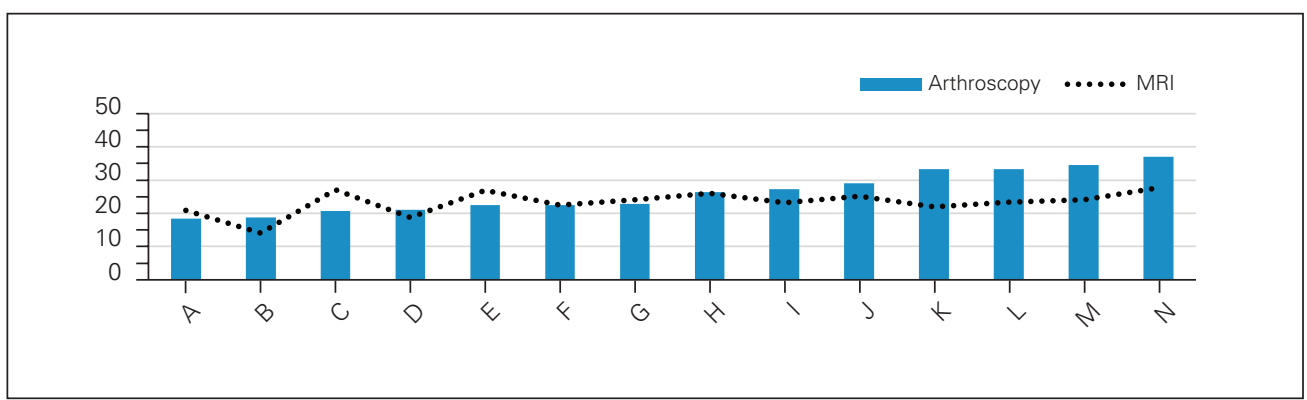

Fig. 4. Proportion of patients who underwent each outcome by geographical area over the 10 -year period. $\mathrm{MRI}=$ magnetic resonance imaging. 
Deveza and colleagues ${ }^{38}$ evaluated whether the frequent use of MRIs in older adults with knee symptoms may be contributing to continued high rates of knee arthroscopies. They found that $25.1 \%$ of patients aged 50 years and older who had a knee MRI underwent arthroscopy in the following 12 months compared with only $3.0 \%$ of patients who received a radiograph. Thus, reducing the unwarranted use of MRI in this population may also help to decrease the overuse of arthroscopy that is likely performed to treat identified degenerative meniscal pathology.

Cohen and colleagues ${ }^{39}$ evaluated preoperative interventions before TKA, reporting an average cost of US\$3500 per patient. Importantly, a high proportion of these costs were interventions that were not supported by clinical evidence and occurred in close proximity to TKA, with about $5 \%-7 \%$ of patients receiving a knee arthroscopy within 1 year of TKA. Further, evidence suggests an increased risk of adverse events, including infection or revision arthroplasty, when arthroscopy is performed within 2 years of TKA. ${ }^{40,41}$

To our knowledge, this is the first study to report the incidence and timing of commonly used yet controversial procedures among a large cohort of patients with knee OA before TKA in a Canadian health care system.

\section{Limitations}

As the present results are based on administrative databases, a limitation includes the potential for inaccurate documentation and coding. Further, given the diagnostic and billing codes available during the study period, we could not specify which joint received the MRI. With the close proximity of the MRI to the TKA and the age of our patient cohort, it is plausible to assume a large proportion was done on the index knee. However, additional studies using prospective primary data collection from patients rather than administrative data are required to determine a more precise estimate of the rates of MRI before TKA.

\section{Conclusion}

The results show that a substantial proportion of patients received diagnostic and therapeutic interventions within close proximity to TKA that lack the support of strong evidence. These results highlight the need for greater knowledge translation and exchange between expert panels, health care providers, patients and payers.

Affiliations: From the Faculty of Health Sciences, Western University, London, Ont. (Marsh, Birmingham); the Bone and Joint Institute, Western University, London, Ont. (Marsh, Birmingham); the Fowler Kennedy Sport Medicine Clinic, London, Ont. (Degen, Giffin, Getgood, Litchfield, Willits); the Schulich School of Medicine and Dentistry, Department of Surgery, Division of Orthopaedics, Western University,
London, Ont. Giffin, Getgood, Litchfield, Willits); the Institute of Clinical Evaluative Sciences (ICES) Western, London, Ont. (McClure, Welk); and the Schulich School of Medicine and Dentistry, Department of Surgery (Urology) Western University, London, Ont. (Welk).

Competing interests: Trevor Birmingham reports receiving grants (paid to institution) from the Canadian Institutes of Health Research, outside the submitted work. Alan Getgood reports receiving consulting fees and research support from Smith and Nephew Inc. and research support form Ossur Inc. Dr. Getgood is on the advisory board of and has stock options with Precision OS and Spring Loaded Technologies. No other competing interests were declared.

Contributors: Ryan Degen, Alan Getgood, J. Robert Giffin, Jacquelyn Marsh, J. Andrew McClure, Blayne Welk and Kevin Willits contributed to the conception and design of the work. Robert Litchfield and Jacquelyn Marsh contributed to the acquisition of data. Trevor Birmingham, Jacquelyn Marsh and J Andrew McClure contributed to the analysis and interpretation of data. Jacquelyn Marsh and Blayne Welk drafted the manuscript. Ryan Degen, Trevor Birmingham, Alan Getgood, J. Robert Giffin, J. Andrew McClure, Robert Litchfield, Blayne Welk and Kevin Willits revised the manuscript critically for important intellectual content. All of the authors gave final approval of the version to be published and agreed to be accountable for all aspects of the work.

Acknowledgements: This study was supported by the ICES Western site. ICES is funded by an annual grant from the Ontario Ministry of Health and Long-Term Care (MOHLTC). Core funding for ICES Western is provided by the Academic Medical Organization of Southwestern Ontario (AMOSO), the Schulich School of Medicine and Dentistry (SSMD), Western University, and the Lawson Health Research Institute (LHRI). The opinions, results and conclusions reported in this paper are those of the authors and are independent from the funding sources. No endorsement by ICES, AMOSO, SSMD, LHRI, or the Ontario MOHLTC is intended or should be inferred. Parts of this material are based on data and/or information compiled and provided by Canadian Institute for Health Information (CIHI). However, the analyses, conclusions, opinions and statements expressed in the material are those of the author(s), and not necessarily those of CIHI.

Content licence: This is an Open Access article distributed in accordance with the terms of the Creative Commons Attribution (CC BYNC-ND 4.0) licence, which permits use, distribution and reproduction in any medium, provided that the original publication is properly cited, the use is noncommercial (i.e., research or educational use), and no modifications or adaptations are made. See: https://creativecommons. org/licenses/by-nc-nd/4.0/

\section{References}

1. Gupta S, Hawker GA, Laporte A, et al. The economic burden of disabling hip and knee osteoarthritis (OA) from the perspective of individuals living with this condition. Rheumatology 2005;44:1531-7.

2. Bitton R. The economic burden of osteoarthritis. Am 7 Manag Care 2009; $15: S 230-5$.

3. Bombardier C, Hawker GA, Mosher D. The impact of arthritis in Canada: today and over the next 30 years. 2011. http://www. arthritisnetwork.ca/downloads/20111022_Impact_of_arthritis.pdf (accessed 2019 Oct. 4).

4. Felson DT. Clinical practice. Osteoarthritis of the knee. $N$ Engl $\mathcal{F}$ Med 2006;354:841-8.

5. Sihvonen R, Paavola M, Malmivaara A, et al. Arthroscopic partial meniscectomy versus sham surgery for a degenerative meniscal tear. NEngl f Med 2013;369:2515-24.

6. Thorlund JB, Juhl CB, Roos EM, et al. Arthroscopic surgery for degenerative knee: systematic review and meta-analysis of benefits and harms. BM7 2015;350:h2747.

7. Kirkley A, Birmingham TB, Litchfield RB, et al. A randomized trial of arthroscopic surgery for osteoarthritis of the knee. $N$ Engl 7 Med 2008;359:1097-107. 
8. Moseley JB, O'Malley K, Petersen NJ, et al. A controlled trial of arthroscopic surgery for osteoarthritis of the knee. $N$ Engl $\mathcal{F}$ Med 2002;347:81-8.

9. Herrlin S, Hallander M, Wange P, et al. Arthroscopic or conservative treatment of degenerative medial meniscal tears: a prospective randomized trial. Knee Surg Sports Traumatol Artbrosc 2007;15:393401.

10. Yim J-H, Seon J-K, Song E-K, et al. A Comparative study of meniscectomy and nonoperative treatment for degenerative horizontal tears of the medial meniscus. Am F Sports Med 2013;41:1565-70.

11. Khan M, Evaniew N, Bedi A, et al. Arthroscopic surgery for degenerative tears of the meniscus: a systematic review and metaanalysis. CMA7 2014;186:1057-64.

12. Marsh JD, Birmingham TB, Giffin JR, et al. Cost-effectiveness analysis of arthroscopic surgery compared with non-operative management for osteoarthritis of the knee. BM7 Open 2016;6:1-10.

13. Bannuru RR, Osani MC, Vaysbrot EE, et al. Snyder-Mackler, McAlindon T.E. OARSI guidelines for the non-surgical management of knee, hip and polyarticular osteoarthritis. Osteoarthritis Cartilage 2019;27:1578-89.

14. Jevsevar DS, Brown GA, Jones DL, et al. The American Academy of Orthopaedic Surgeons evidence-based guideline on: treatment of osteoarthritis of the knee, 2nd edition. J Bone Joint Surg Am 2013;95:1885-6.

15. Fernandes L, Hagen K, Bijlsma J, et al. EULAR recommendations for the non-pharmacological core management of hip and knee osteoarthritis. Ann Rheum Dis 2013;72:1125-35.

16. Hochberg M, Altman R, April K, et al. American College of Rheumatology 2012 recommendations for the use of nonpharmacologic and pharmacologic therapies in osteoarthritis of the hand, hip, and knee. Artbritis Care Res 2012;64:465-74.

17. National Institute for Health and Care Excellence. Osteoarthritis. GC177. NICE, 2014

18. Sakellariou G, Conaghan PG, Zhang W, et al. EULAR recommendations for the use of imaging in the clinical management of peripheral joint osteoarthritis. Ann Rheum Dis 2017;76:1484-94.

19. Quality-Based Procedures Clinical Handbook for Primary Hip and Knee Replacement. Available: http://www.health.gov.on.ca/en/pro/ programs/ecfa/docs/qbp_prihipknee.pdf (accessed 2019 Oct. 4).

20. Adelani MA, Mall NA, Brophy RH, et al. The use of MRI in evaluating knee pain in patients aged 40 years and older. 7 Am Acad Orthop Surg 2016;24:653-9.

21. Menashe L, Kirko K, Losina $\mathrm{E}$ et al. The diagnostic performance of MRI in osteoarthritis: a systematic review and meta-analysis. Osteoarthritis Cartilage 2012;20:13-21.

22. Englund M, Guermazi A, Gale D, et al. Incidental meniscal findings on knee MRI in middle-aged and elderly persons. $N$ Engl 7 Med 2008;359:1108-15.

23. Sakellariou G, Conaghan P, Zhang W, et al. EULAR recommendations for the use of imaging in the clinical management of peripheral joint osteoarthritis. Ann Rheum Dis 2017;76:1484-94.

24. Culvenor AG, Øiestad BE, Hart H, et al. Prevalence of knee osteoarthritis features on magnetic resonance imaging in asymptomatic uninjured adults: a systematic review and metaanalysis. Br 7 Sports Med 2019:53:1268-78.

25. Kemp MA, Lang K, Dahill M, et al. Investigating meniscal symptoms in patients with knee osteoarthritis: Is MRI an unnecessary investigation? Knee 2011;18:252-3.
26. Peter C, Daly PA, Tu JV. A multicenter study of the coding accuracy of hospital discharge administrative data for patients admitted to cardiac care units in Ontario Canada. Am Heart $72002 ; 144: 290-6$.

27. Gershon AS, Wang C, Guan J et al. Identifying individuals with physcian diagnosed COPD in health administrative databases. COPD 2009;6:388-94.

28. Quan H, Khan N, Hemmelgarn BR, et al. Validation of a Case Definition to Define Hypertension Using Administrative Data. Hypertension 2009;54:1423-8.

29. Hux JE, Ivis F, Flintoft V, et al. Diabetes in Ontario determination of prevalence and incidence using a validated administrative data algorithm. Diabetes Care 2002;25:512-6.

30. Widdifield J, Bernatsky S, Paterson JM et al. Accuracy of Canadian health administrative databases in identifying patients with rheumatoid arthritis: a validation study using the medical records of rheumatologists. Arthritis Care \& Research 2013;65:1582-91.

31. Benchimol EI, Smeeth L, Guttmann A, et al.; RECORD Working Committee. The REporting of studies Conducted using Observational Routinely-collected health Data (RECORD) statement. PLoS Med 2015;12:e1001885.

32. Hawker G, Guan J, Judge A, et al. Knee arthroscopy in England and Ontario: patterns of use, changes over time, and relationship to total knee replacement. F Bone foint Surg Am 2008;90:2337-45.

33. Wai EK, Kreder HJ, Williams JI. Arthroscopic débridement of the knee for osteoarthritis in patients fifty years of age or older: utilization and outcomes in the province of Ontario. 7 Bone foint Surg Am 2002;84:17-22

34. Health Quality Ontario; Ministry of Health and Long-Term Care. Quality-based procedures: Clinical handbook for knee arthroscopy. Toronto: Health Quality Ontario; 2014 December. 68 p. Available from: http://www.hqontario.ca/evidence/evidence-process/episodes -of-care\#knee-arthroscopy (accessed 2019 Oct. 4).

35. Degen RM, Lebedeva Y, Birmingham TB, et al. Trends in knee arthroscopy utilization: a gap in knowledge translation. Knee Surg Sports Traumatol Arthrosc 2020;28:439-47.

36. Dhawan A, Mather RC, Karas V, et al. An epidemiologic analysis of clinical practice guidelines for non-arthroplasty treatment of osteoarthritis of the knee. Artbroscopy 2014;30:65-71.

37. Abram SGF, Judge A, Beard DJ, et al. Rates of knee arthroplasty within one-year of undergoing arthroscopic partial meniscectomy in England: temporal trends, regional and age-group variation in conversion rates. Osteoarthritis Cartilage 2019;27:1420-9.

38. Deveza LA, Mathews L, O'Connell R, et al. Is the use of knee magnetic resonance imaging one of the drivers of persistently high arthroscopy rates in older adults? - an analysis of national data in Australia. Osteoarthritis and Cartilage 2018;26:S249.

39. Cohen JR, Bradley AT, Lieberman JR. Preoperative interventions and charges before total knee arthroplasty. F Arthroplasty 2016;31:2730.

40. Gu A, Malahias MA, Cohen JS, et al. Prior knee arthroscopy is associated with increased risk of revision after total knee arthroplasty. $\mathcal{F}$ Arthroplasty 202035:100-4.

41. Werner BC, Burrus MT, Novicoff WM, et al. Total knee arthroplasty within six months after knee arthroscopy is associated with increased postoperative complications. 7 Artbroplasty 2015;30:1313-6. 